\title{
Spatializing design history: Considerations on the use of maps for studies on print culture
}

\author{
Priscila Lena Farias / Daniela Kutschat Hanns / University of São Paulo / \\ São Paulo / Brazil
}

Catherine Dixon / Central Saint Martins / University of the Arts London / London / UK

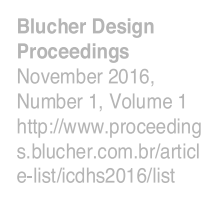

\begin{abstract}
In the last decades, there has been a growing interest in the use of geographic information for historical research. Parallel to that, there has also been an increasing interest for data visualization as an aspect of information design, leading to a significant number of studies and developments in the field of cartographic design. The main argument of this essay is that historical GIS and spatial history are relevant approaches for design history. This is demonstrated with examples of research on the history of typography and print that benefited from the use of analogical and digital maps.
\end{abstract}

\section{Keywords}

Graphic design, design history, graphic memory, typography, spatial history, historical GIS

\section{Introduction}

Since the 1980's, as part of what has been described as the 'spatial turn' in the humanities, a growing interest in applying spatial data and geographic information to studies in various fields, and in particular to historical research, has been recorded by various authors (among them, Urry 1990, Warf \& Arias 2008, Withers 2009). According to Knowles (2008, p. 4), the French Annales school, and in particular Fernand Braudel's idea of geohistoire, along with Paul Carter's concept of 'spatial history' (Carter 1987) are some of the main precursors of this line of inquiry, which eventually gave rise to current historical GIS. In a more recent definition of spatial history, White (2010) mentions Henri Lefebvre and William Cronon as authors who contributed to the idea of considering space as central to understanding history, but describe them as exceptions within colleagues that 'still routinely write about political change, social change, class relations, gender relations, cultural change as if the spatial dimensions of these issues matter little if at al' (White 2010, p. 2).

Geographic Information Systems (GIS) are computer systems developed to gather, organize and visually render spatial data (for a more detailed and nuanced definition, see Maguire 1991). Although geo-referenced data is of course central to GIS databases, it can be, and very often is, combined with other kinds of information. In the case of historical GIS, or of systems intended to deal with dynamic events, spatial data is combined with temporal data and to data related to system elements' attributes and relationships (Peuquet 1994, Andrienko et al 2003, Pérez Asensio et al 2012). Examples of historical GIS include detailed studies of very specific areas in short periods of time, like the Battle of Gettysburg, Pennsylvania in July 1863, and very broad infrastructural projects like the China Historical GIS - a system developed to combine spatial and temporal data related to the territory and population of China from 222 BC to 1911 AD (both described in Knowles 2008).

Within the field of information design, the interest for dynamic and interactive maps has also been growing since the 1980's, along with the development of digital tools and communication networks. Two whole chapters of a recent compendium on infographics (Meirelles 2013) are dedicated to maps and 'spatio-temporal' structures, and examples of 'relational' and 'textual' visual structures based on geographic representations are highlighted in other chapters. Many examples of how designers and artists have approached the quest of mapping territories and networks in physical and virtual space, including locative media applications, navigation systems, dynamic diagrams and computer animations have been gathered in Abrams \& Hall anthology Else/where: mapping (Abrams \& Hall 2006). 


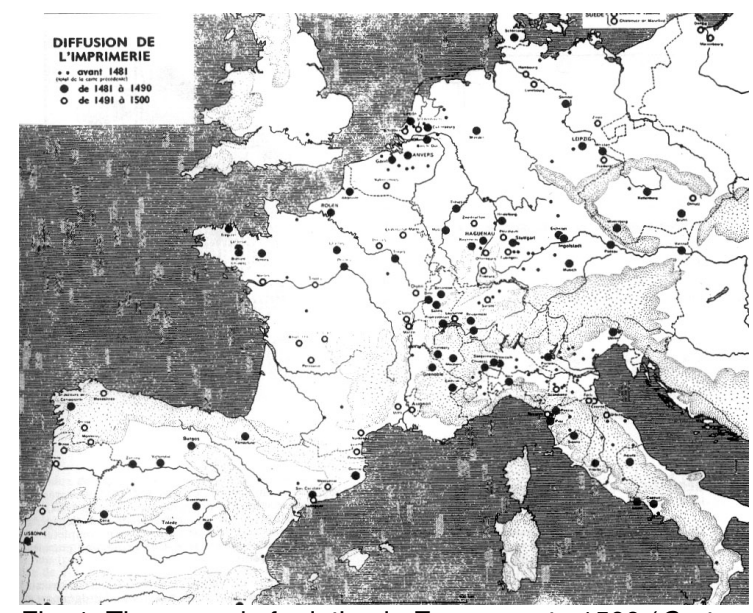

Fig. 1: The spread of printing in Europe up to 1500 (Carte no. 2, Febvre \& Martin 1958, p. 295)

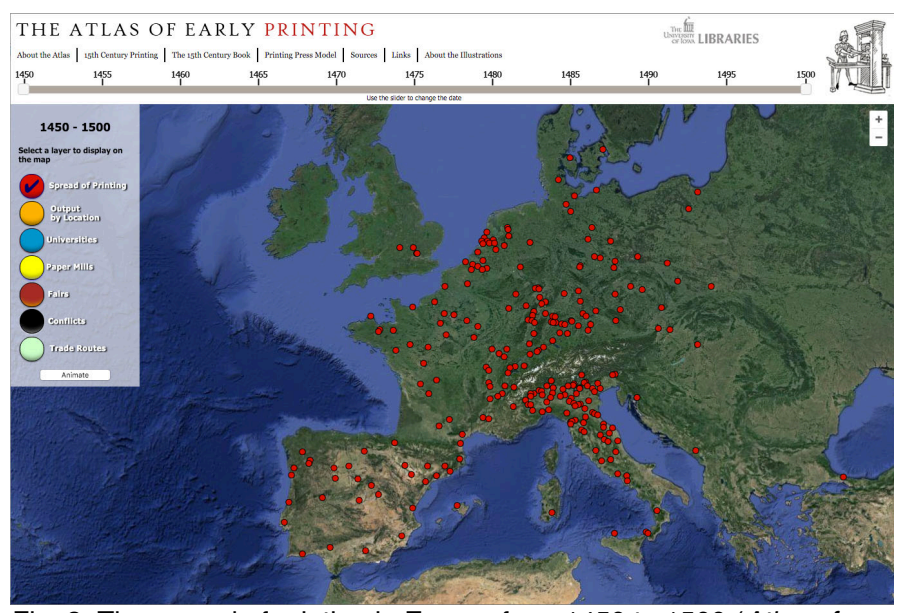

Fig. 2: The spread of printing in Europe from 1450 to 1500 (Atlas of Early Printing)

In what regards possible contributions between the fields of geography, information design and design history, an early argument in favour of collaboration has been put forward by Woodward (1985). According to the author, 'maps are among the most intensely designed graphic products of man's material culture. [...] It would be curious, indeed, if the study of maps and their design could not shed some light on the field of design history in a real, as well as metaphorical, sense' (Woodward 1985, p. 69). Despite the traditional use of cartography in fields like architecture, landscape or urban design, a specific argument for the use of maps and mapping technologies in design history research - for spatializing design history, in the sense suggested here-, has not yet been done.

\section{Spatializing print}

If we consider print culture and the history of the book as part of (graphic) design history, the most famous and influential demonstration of the relevance of maps for the understanding of cultural, economic, social, and technological change within the field can be found in Lucien Febvre and Henri-Jean Martin's L'apparition du livre (1958). Building on the pioneer work of François de Dainville on book publishing in France between 1764 and 1945 (Bousquet-Bressolier 2002, pp. 28-31), Febvre and Martin base their discussion of the geography of the book and of publishing on two maps, showing the location of printing offices in Europe up to 1500, which are used as visual evidence for their arguments on the spread of printing. In a recent literature review on the geography of the book, Keighren (2013) calls for a wider approach, that would not be limited, as 'much (although not all) extant scholarship', on 'the printed (non-fiction) book' (p. 752).

Much of what is described as studies on print culture, and even on the history of print or of typography, are in fact studies on book production, based on the point of view of editors and authors. As argued elsewhere (Farias 2014), the study of print culture should not be restricted to books or to graphic artefacts produced with letterpress - and therefore should include all kinds of other printed things, like lithographed sheet music, silk-screened posters and photocopied fanzines. Also, taken as an approach to design history, it is not sufficient to consider printed artefacts as abstract entities that circulate between authors, editors and readers - material and formal aspects have to be taken into account too.

Twyman's directory of London lithographic printers (Twyman 1976) is, in this sense, a pioneering effort in the visualization of historical data related to print culture. The growth in number of printers in the first half of the nineteenth century is shown in two diagrams, combining a bar chart and a more detailed timeline of a critical period. A series of maps in the last pages of the book, based on old city plans, shows where the printing shops were located, and also how the geographic distribution of printers evolved over time. The spatialization of the otherwise purely textual information serves as a basis for the author's interpretation of historical data: maps clearly show a tendency for printer's addresses to move from Westminster towards the City, while the kind of job the majority of them specialized in also changed, from artistic to commercial. The relative frequency in the change of address of specific printers, and the occasional occupation of the same premise by more than one printer, are other spatio-temporal data observed by Twyman that, although not visually rendered, provide information on the size and working habits of nineteenth century lithographic printers. 


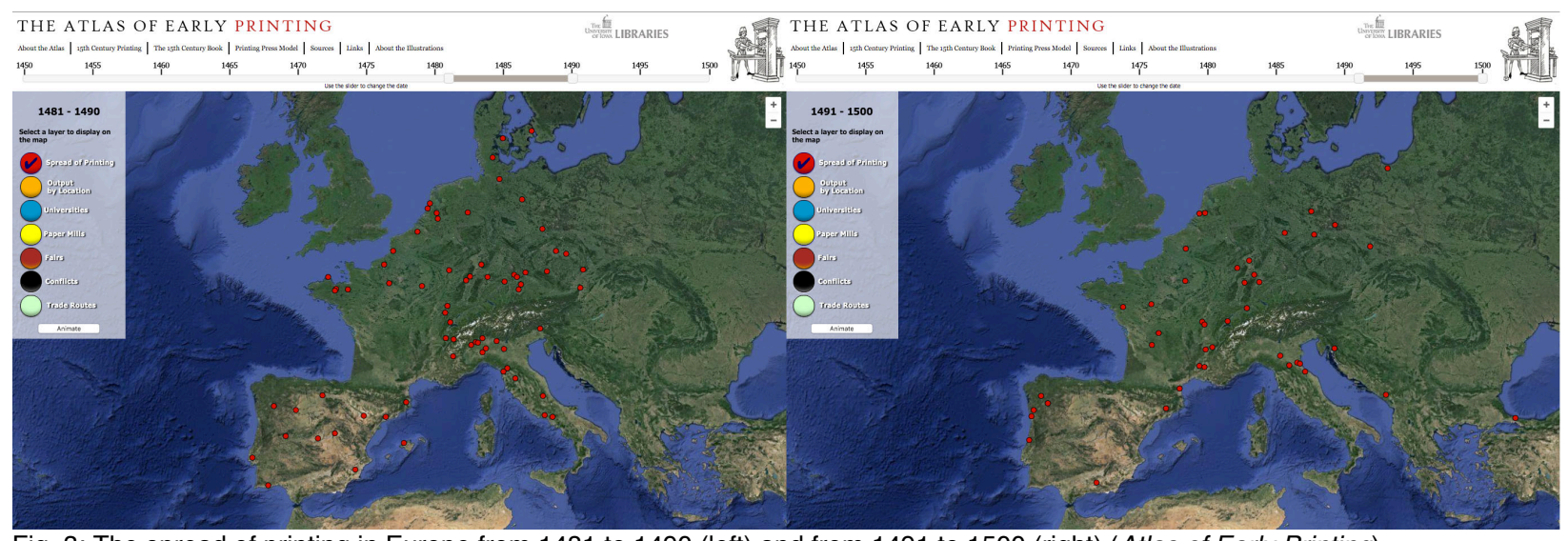

Fig. 3: The spread of printing in Europe from 1481 to 1490 (left) and from 1491 to 1500 (right) (Atlas of Early Printing)

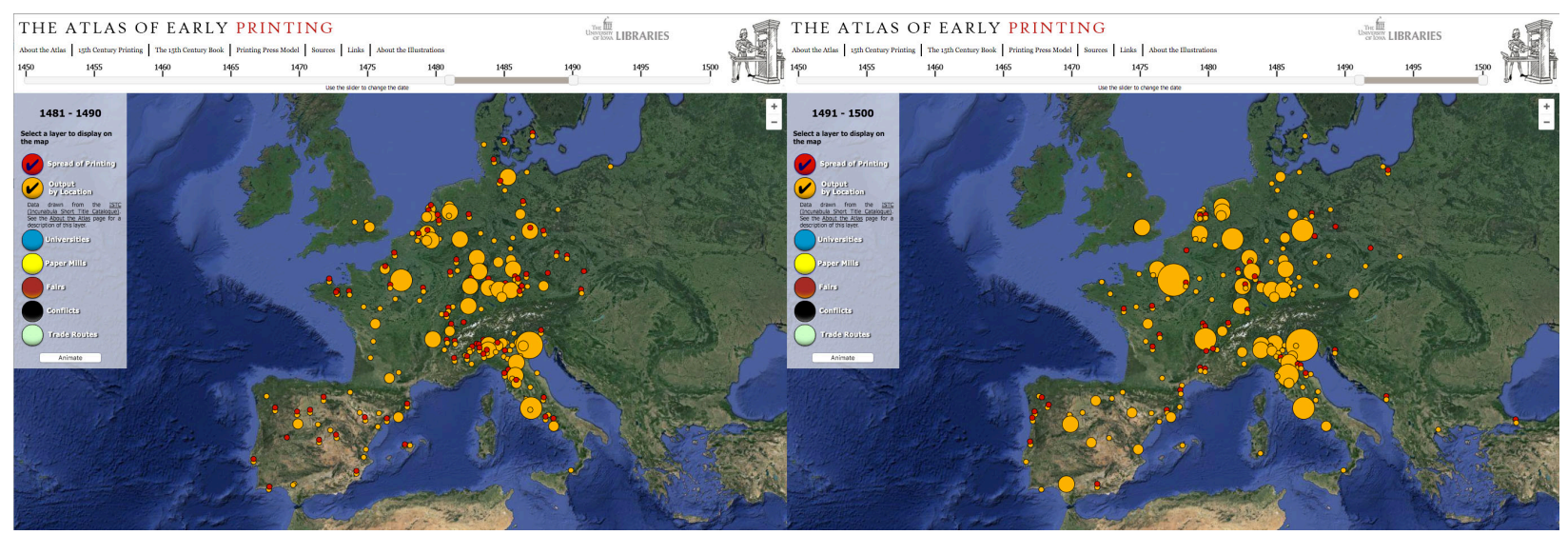

Fig. 4: The spread of printing in Europe and output by location from 1481 to 1490 (left) and from 1491 to 1500 (right) (Atlas of Early Printing)

In their review of the use of GIS for studies on print culture, MacDonald and Black (2000) correctly start by characterizing print culture in a wide sense, but all the cases they discuss are based on book (or newspaper and book) history datasets. One of the examples discussed by the authors is the Historical Atlas of Canada, a publication that, in its current online version, ${ }^{1}$ includes interactive maps showing information on local extant libraries (date of foundation, location, number of volumes) and published newspapers (location, circulation, political viewpoint, spread) from 1752 to 1900 .

According to MacDonald and Black (2000, pp. 513-515), GIS technologies allows for the visualization and analysis of wide and complex datasets, providing support for 5 kinds of queries: location (attributes of a given place), condition (locations fulfilling certain conditions), trends (changes in attributes over time), patterns (spatial distribution) and projections or models (potential patterns based in past data). As for the types of research endeavour facilitated by the use of GIS, the authors list "the "simple" mapping of individual factors; the analysis and subsequent mapping of interrelationships between and among several factors from a single database; and the analysis and report generation (with or without mapping) of information drawn from disparate source databases (MacDonald and Black 2000, p. 517).

While an analogical or printed map serves well as a piece of evidence within a printed or otherwise static text, interactive maps and GIS are better as heuristic tools and for testing theories and assumptions. Examples of the first are the maps used by Febvre \& Martin (1958, pp. 219, 295) to ground their interpretation of the spread of print in Europe. Precise as they might be, they do not allow for experiments or tests unless one redraws them. The interactive map available in the Atlas of Early Printing, ${ }^{2}$ on the other hand, allows for many different visualizations, combining date (from 1940 to 1500), the location of printing shops, universities, paper mills, fairs, conflicts and trade routes. Because one of the sources of data regarding the spread of printing in the Atlas of Early Printing is Febvre \& Martin (1958), it is possible to obtain, for example, a map comparable to the French authors' Carte no.2 (figure 1).

\footnotetext{
${ }_{1}^{1}$ Available at <http://www.historicalatlas.ca/website/hacolp/national_perspectives/society/UNIT_35/index.htm> [8 Feb 2016]. 2 The Atlas of Early Printing was created by Greg Prickman, Head of Special Collections \& University Archives at the University of lowa Libraries (USA), and made available in 2013 at <http://atlas.lib.uiowa.edu/> [8 Feb 2016].
} 
Once the Atlas of Early Printing does not have visual variations for locations related to different periods of time, the representation of the whole era results homogeneous and less informative (figure 2). The comparison between specific periods, however, becomes clearer when examined separately (figure 3). Combining the location of printing shops with data regarding the output of each location, drawn from the British Library Incunabula Short Title Catalogue, it is possible to observe that while the overall number of printing shops decreased, the output of some of them significantly increased in the last decade of the fifteenth century (figure 4).

Interactive maps and GIS are frequently conceived with several layers of information (Gregory 2005 , p. 19), by means of which spatial and temporal data are combined with data related to element's attributes and relationships between elements. Element's attributes, in most current print culture GIS, are usually given in written verbal language only. In the case of the Atlas of Early Printing, by clicking on each dot in the map we have access to strictly textual information on the printing shops, universities, paper mills, fairs, and conflicts they refer to. The same is true for the public libraries and newspapers in the Historical Atlas of Canada 'The Printed Word, 1752-1900' interactive map. As for relationships between elements, 'The Printed Word' map includes the visualization of the 'spread of newspapers', where 'transplants' of newspapers from one city to another are represented by oriented arrows (figure 5).

From the point of view of graphic design history, as well as for the concerns of analytical bibliog-

raphy, however, some key questions remain: What do those books, newspapers and printed outputs looked like? What kinds of letters and images do they used? How were those printed artefacts configured, visually and materially?

The Bulgarian book history from the Liberation to Independence of Bulgaria (1878-1908) ${ }^{3}$ seems to be one of the few print culture GIS initiatives so far to include visual information on the published material -in this case, images of title pages of Bulgarian books, associated with a timeline (although not with the interactive map itself). Another initiative is the Geocontexting the Printed World $1450-1800^{4} \mathrm{GIS}$, an ongoing project that intends to connect maps and information on early (and so far only European) printers with a huge collection of initials and ornaments used by them. The reconstruction of the typographic repertoire of nineteenth century São Paulo city printers is the focus of an ongoing research coordinated by the authors of this paper, and should result in a website ${ }^{5}$ that combines georeferenced data (printing shop locations) with information about printers and their outputs (newspapers, books, almanacs and ephemera).

Plans for creating a comprehensive database of typographic elements are discussed by Dijstelberge (1998), and an example of the procedures adopted for identifying and reconstructing part of the typographic repertoire of a nineteenth century São Paulo city printer are presented in Farias \& Onoda (2015). A database such as

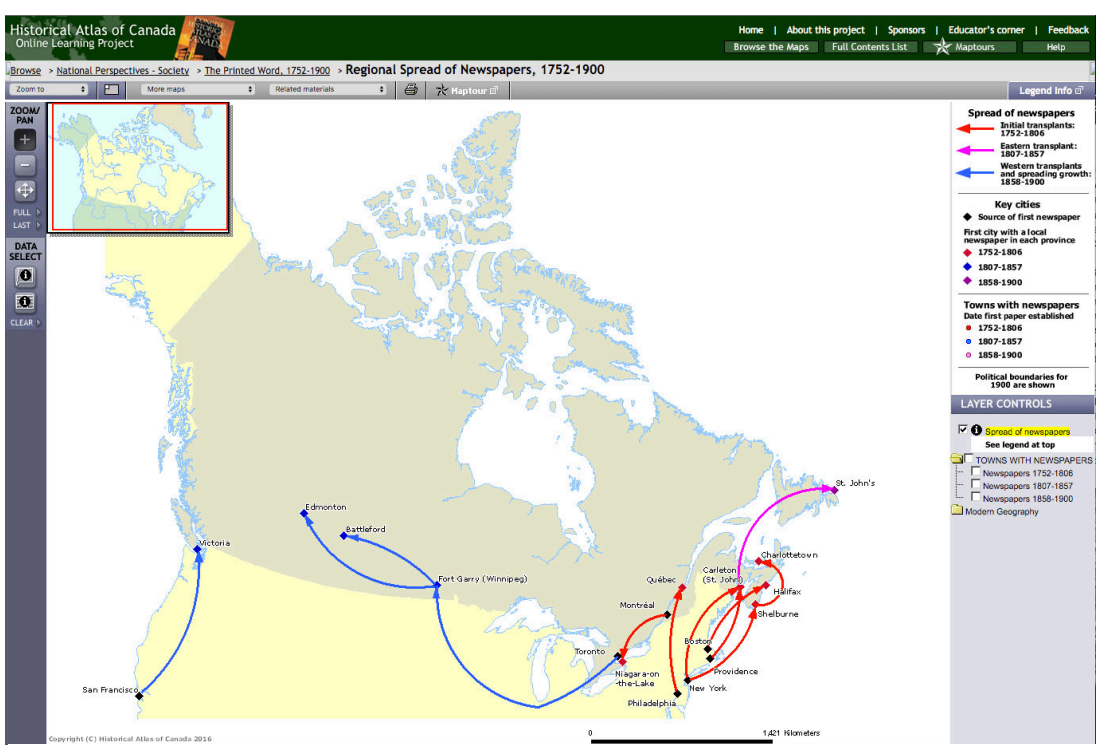

Fig. 5: The spread of newspapers in Canada (1752-1900) ('The printed word, 17521900', Historical Atlas of Canada) that envisioned by Dijstelberge (1998) would facilitate the comparisons between different printers and type founders repertoires carried out by Farias \& Onoda (2015), and its spatialization would provide support for arguments about of the circulation of typeforms such as those suggested in Farias et al (2012, pp. 509-510) and Farias \& Onoda (2015, p. 891). Initiatives such as these should build up a more detailed and complex history of print and visual culture, which might eventually provide new knowledge regarding the transnational networks created by the circulation of typefaces and typographic styles.

\footnotetext{
${ }^{3}$ Result of a research project coordinated by Vasil Zagorov, a professor and Head of Library Studies Department at the University of Library Studies and Information Technologies in Sofia (Bulgaria), available at <https://bgbookhistory.unibit.bg/en> [8 Feb 2016].

${ }^{4}$ A preview of this project, developed by Paul Dijstelberge, from the Universiteit van Amsterdam (Netherlands), is available at $<$ http://arkyves.org/view/geocontext> [8 Feb 2016].

${ }^{5}$ The current version of the site is available at <http://www.fau.usp.br/tipografiapaulistana/> [8 Feb 2016].
} 


\section{Discussion}

Spatializing design history, by locating historical information in maps, in particular in digital and interactive maps, allows for the observation of patterns and trends that are otherwise difficult to detect, especially when dealing with large amounts of data. GIS technologies and digital maps dedicated to that should combine spatial and temporal data with element attributes rich enough to describe design artefacts and the agents involved in its production (an eventually also of its circulation and discard), as well as the relationships between those elements.

If historical GIS are to be relevant to design history and design studies, it is crucial that they include visual representations of the artefacts involved, besides the also relevant textual and numerical data. The absence visual data in the GIS dedicated to print culture presented above might be interpreted as research field bias (visual information might have seem to be secondary or of no importance for some researchers), but also as the result of a difficulty in dealing with images as data, or to have access to comprehensive and relevant image datasets.

In the case of print culture GIS, the dominance of books, in detriment of other printed matter, is certainly related to the difficulty of finding library collections that include anything other than books, and in particular archives that include ephemera like posters, packaging and catalogues. The incorporation of visual datasets generated by the growing digitalization of books and printed matter collections around the globe might be just a matter of time and also, in some cases, of financial support. The level of detail and the resolution and size of those images will also have to be considered, depending on the task at hand. Minute observation of typefaces in small body sizes, for instance, require images in a resolution level much higher than the one needed for examining the overall typographic arrangement of a poster.

Finally, if we are to consider not only the production, but also the circulation and eventual discard of designed artefacts, better strategies for the visualization and analysis of connections between locations, and of changes in space through time must be devised. Although all maps in figures 1 to 5 above represent 'the spread' of printed documents (an event that involves changes in space through time), only one includes the visualization of the direction of such 'spread' by means of connections between locations (figure 5). The two others require the comparison of different patterns of locations distribution, something that demands cognitive effort of abstraction (figure 1), or practical effort of producing and comparing two different static images of an interactive map (figure 3 ).

In the concluding topic of 'Using GIS for spatial and temporal analyses in print culture studies', MacDonald \& Black (2000) predicted that 'macrostudies examining whole countries or analyses of the interplay of print culture factors in an international context [would] emerge when there are datasets of sufficient quantity and size to make it feasible to employ GIS', and argued that until then the technology would be applied to microlevel cases, based on 'relatively narrow geographic areas and time periods' (MacDonald \& Black 2000, p. 257-258).

More than 15 years after, if we agree on the need to achieve a better understanding of the transnational aspects of design history, the effort of creating consistent datasets for visualising and analysing spatiotemporal aspects of the field, even if just for microlevel cases, is still worthwhile. This effort should be combined with the best practices of data visualization, that design itself can provide.

\section{Acknowledgement}

The research presented in this paper was financially supported by grants from FAPESP and CNPq.

\section{References}

Abrams, J., \& Hall, P. (Eds.) (2006). Else/where: Mapping: New cartographies of networks and territories. Minneapolis: University of Minessota.

Andrienko, N., Andrienko, G., \& Gatalsky, P. (2003). ‘Exploratory spatio-temporal visualization: An analytical review'. Journal of Visual Languages \& Computing, vol. 14, no. 6), pp. 503-541.

Bousquet-Bressolier, C. (Ed.) (2002). François de Dainville S.J. (1909-1971): Pionnier de l'histoire de la cartographie et de l'éducation. Paris: École des Chartes.

Carter, P. (1987). The road to Botany Bay: An essay in spatial history. London: Faber and Faber.

Dijstelberge, P. (1998). 'Towards a Digital Atlas of initial letters and typographic ornaments in the Netherlands'. Quaerendo, vol. 28, no. 3, pp. 215-224.

Farias, P. L., Aragão, I. R., \& Cunha Lima, E. L. (2012). 'Unravelling aspects of Brazilian design history through the study of 19th century almanacs and type specimens'. Conference Proceedings: Design Research Society 2012: Bangkok, vol. 2, pp. 498-511. 
Farias, P. L., \& Onoda, M. A. (2015). 'Letras toscanas no repertório tipográfico de Jorge Seckler (18831895)'. Proceedings of the 7th Information Design International Conference - CIDI 2015, pp. 883-892.

Febvre, L., \& Martin, H.-J. (1958). L'apparition du livre. Paris: Albin Michel.

Gregory, I. N. (2005). A place in history: A guide to using GIS in historical research ( $2^{\text {nd }}$ edition). Belfast: Centre for Data Digitisation and Analysis.

Keighren, I. M. (2013). 'Geographies of the book: Review and prospect'. Geography Compass, vol. 7, no. 11, 745-758.

Knowles, A. K. (Ed.) (2008). Placing history: How maps, spatial data, and GIS are changing historical scholarship. Redlands: ESRI.

MacDonald, B. H., \& Black, F. A. (2000). 'Using GIS for spatial and temporal analyses in print culture studies'. Social Science History, vol. 24, no. 3, pp. 505-536.

Maguire, D. J. (1991). 'An overview and definition of GIS', in D.J. Maguire, M.F. Goodchild and D.W. Rhind (Eds.) Geographical Information Systems: Principles and applications. Volume 1: principles. Harlow: Longman, pp. 9-20.

Pérez Asensio, E., Del Bosque González, I., Maestre Martínez, R., Crespo Solana, A., \& Sánchez-Crespo Camacho, J. M. (2012). 'Modelling and Implementation of a spatio-temporal historic GIS'. Journal of Knowledge Management, Economics and Information Technology: Self-organizing Networks and GIS Tools Cases of Use for the Study of Trading Cooperation (1400-1800) (special issue), June 2012, pp. 145-189.

Peuquet, D. J. (1994). 'It's about time: A conceptual framework for the representation of temporal dynamics in geographic information systems'. Annals of the Association of American Geographers, vol. 84, no. 3, pp. 441461.

Twyman, M. (1976). A directory of London lithographic printers, 1800-1850. London: Printing Historical Society.

Urry, J. (1990). 'Work, production and social relations'. Work, Employment \& Society, vol. 4, no. 2, pp. 271 280.

Warf, B., \& Arias, S. (Eds.) (2008). The spatial turn: Interdisciplinary perspectives. Routledge.

White, R. (2010). 'What is spatial history?'. Spatial History Lab: Working paper, Stanford University Spatial History Lab. Available: http://www.stanford.edu/group/spatialhistory/cgi-bin/site/pub.php, [8 Feb 2016].

Withers, C. W. J. (2009). 'Place and the "spatial turn" in geography and in history'. Journal of the History of Ideas, vol. 70, no.4, pp. 637-658.

Woodward, D. (1985). 'Cartography and design history: A commentary'. Design Issues, vol. 2, no. 2, pp. 6971.

\section{Biographical note}

Priscila Farias is a graphic designer and a professor at the University of São Paulo School of architecture and urbanism, where she coordinates the visual design research lab and the design BA. She holds a PhD in communication and semiotics from the Pontifical Catholic University of São Paulo.

Daniela Kutschat Hanns is an artist who works with interactive art and design and visualisation systems. Doctor in arts, she is a professor at the University of São Paulo School of architecture and urbanism, where she works at the visual design research lab.

Dr Catherine Dixon is a senior lecturer in typography at Central Saint Martins (UAL). Research areas include the history of typeface design and its classification, public lettering, and the role of letterpress in design education. She was a Visiting Professor at the University of São Paulo, Brazil from 2011-12. 